\title{
DEVELOPMENT OF A BLENDED COURSE IN ENGLISH FOR INTERNATIONAL STUDENTS IN MECHANICAL ENGINEERING
}

\author{
Valentina Deryusheva $^{1}$, and Evgeniia Frantsuzskaia ${ }^{1,}$ a \\ ${ }^{1}$ Tomsk Polytechnic University, 634050 Lenin Avenue, 30, Tomsk, Russia
}

\begin{abstract}
Modern requirements for a technical university graduate in their language proficiency affect the quality of training of a lecturer delivering the teaching and learning process. The growth of the number of international students and redistribution of the number of teaching hours with now prevailing amount of independent work of students lead to development of blended educational courses in English. The authors suggest their viewpoint on the design of a blended educational course in English for international students.
\end{abstract}

\section{Introduction}

Internationalization practice of higher education in modern Russia and its integration into the world educational space lead to some significant changes both in the structure and the content of specialists' education. Besides providing access to high quality education and acquiring competencies for global and sustainable development and improving the general quality of education, internationalization goals also include developing of research, cooperating with the world society and searching for global problem solutions [1]. Consequently, the importance of the communicative competence of university graduates increases, which enables them to discuss professional and scientific topics with their international colleagues, perform an independent search and analysis of authentic in formation in the sphere of professional communication.

As a result there is a change in requirements for the training of faculty, who are responsible for the teaching and learning process. National Research Tomsk Polytechnic University, Tomsk, Russia (TPU), describes its demands to the quality of training of faculty, who deliver educational courses for domestic and international students, in a number of documents. For instance, the Strategic program of Competitiveness Enhancement in the Group of Top Level World Research and Academic Institutions lists such requirements as the sufficient language proficiency to enable the faculty to communicate with an international partner in order to develop and realize reasearch and educational projects, publish research papers in international journals with a high impact factor and teach international students in English. To reach the goals set in the Strategic Program, TPU gradually and systematically shapes the university polylingual environment [2]. Recent modifications in the student body with the increasing number of international students have required fast development of new educational programs and disciplines (or modules of disciplines) to be delivered in English.

\section{Faculty professional enhancement}

To provide faculty delivering the teaching and learning process in English with appropriate training, TPU has developed and successfully realized its articulate system of faculty professional enhancement in the field of language training. In particular, it is possible to mention several key directions of training that empower to achieve better results in addressing goals of internationalization and university competitiveness enhancement:

- language proficiency courses;

- courses to develop an educational course (modules of professional training and professional disciplines) in English;

- courses to prepare a scientific paper to be publish in a journal from the world citation base;

- courses to manage document flow in English [3].

These courses are aimed at different target audiences, which include not only faculty but also research and administrative and managerial university staff. All these categories are to demonstrate sufficient language proficiency in their professional activities.

Faculty of non-linguistic majors whose language proficiency is sufficient for teaching in English attend professional enhancement courses, which result in development of an educational course (face-to-face classroom, online or blended).

In terms of the professional training in this field, the authors have developed the blended educational course

\footnotetext{
a Corresponding author: francuzskaya@tpu.ru
} 
"Mathematical modeling" in English for international students in Mechanical Engineering.

\section{Course contents and structure}

The course "Mathematical modeling" is one of fundamental disciplines in Mechanical Engineering. The discipline develops the learners' non-technical and professional skills focused on training a future engineer in the field of modern machinery, construction and installation production based on resource-effective technologies. The specialist who will be we-trained for independent creating innovative technologies for producing machinery, construction and installation products and objects and means of their tooling.

The course "Mathematical modeling" implies teaching and learning the theoretical grounds for modeling process on modern software. Structurally the course contains lecturing and seminar sessions as well as laboratory work with the prevailing amount of independent work of students.

With the target audience of international students, the course is being delivered in English. This allows applying authentic English literature and software in English. The blended model of study permits to optimize the classroom work with the help of modern teaching technologies and active methods of teaching and to manage independent students' work in the electronic environment.

\section{E-learning vs blended learning}

Electronic courses in their wide diversity are frequently used in modern teaching. The undeniable advantages of electronic courses are their accessibility, individual approach to learners, the opportunity to catch up with the material missed for some reasons in the classroom, development of individual work and time management skills, effective use of assessment materials, ability to combine various types of teaching information and interaction of the electronic environment and the learner. Electronic courses are a perfect base for computer graphics, animation, video, sound and other media components for better material visualization. Electronic courses allow $60 \%$ increase in the efficiency of teaching and learning as they provide practical use of the knowledge received.

The potential drawbacks of pure electronic education, primarily, address the digital literacy of a learner, which can be solved with some pre-sessional training. There are some disadvantages referring to the material incompatibility, which is actually the problem of standards, and the material inflexibility. The latter means that it is quite complicated to make any adjustment to the course materials when the course is running, as pure elearning does not allow the teacher to see the students' immediate reaction to the materials, so all the changes have to be done afterwards. Besides, electronic courses are often not suitable for certain types of activities, which does matter for courses devoted to language teaching or focused on developing professional communicative competence. Finally, the electronic environment does not offer a self-enhancing pedagogical environment to its learners [4].

These disadvantages of electronic courses are to be avoided, the most effective is use of the blended model, which allows combining the traditional classroom student work under the teacher's supervision and the autonomous student work in the electronic environment [5].

Blended courses demonstrate advantages for various groups of those involved. For instance, a university strategy to compensate for limited classroom space and number of contact teaching hours finds its way in blended courses. Blended courses design make faculty think and collaborate differently in comparison with traditional classroom teaching. Such courses also open new engagement opportunities into established courses.

Students are offered the conveniences of online learning method and social and instructional opportunities from their teacher and group-mates. The functions of the teacher in the blended model transforms greatly as no direct knowledge transition exists any more but the teacher manages and coordinates the whole process and the course materials [6].

The authors' task was to design the electronic element of the blended course "Mathematical modeling" in English for international students in Mechanical Engineering. The discipline curriculum contains the prevailing number of independent hours so the course cannot be taught traditionally in the face-to-face format to its full degree. It was decided to arrange some classroom and all the necessary study materials for independent study in the electronic environment.

The developed blended course is based on the key didactic principles and active methods of teaching which are widely applied in the modern teaching and learning process of a university.

\section{Online course contents and structure}

The electronic element of the blended course supports the classroom activities structurally and in its content so that it can be used both for teaching in class and for independent work of the students. The electronic course "Mathematical modeling" is structurally divided into several thematic modules. Each of them has a clear structure containing theoretical materials resumed from the lecturing sessions and some practical tasks followed by a video manual and a set of written instructions. Such structure enables keeping the student motivation for further work rather high as it is based on the principle of difficulty distribution.

The tasks that the students receive in the class generally follow the structure of the video manuals so that it helps to consolidate the knowledge and drill the material. The students get their individual tasks to do and to submit them in the electronic environment of the blended course. The individual tasks require the practical application of the received knowledge and practiced skills to solve a particular problem. The teacher provides the feedback through the tools of the electronic course 
such as "Forum" and "Chat" and also through commenting the students' answers and analyzing typical mistakes further in class. Taking into consideration the errors occurred, the teacher develops some further recommendations for the students and makes necessary changes into the teaching and learning materials [6].

The initial stage of the course demands the compulsory introductory session about the basics of digital literacy and the peculiarities of the course realization. The students are taught how to use the tools of the electronic environment, how to submit tasks and how to watch a video embedded into the course. As the teaching experience demonstrates, the levels of digital literacy within one group of students may vary greatly so this step is regarded as essential [7].

Problem-based teaching approach as one of active methods of teaching and learning is supposed to be the most effective technology to be used in groups of international students. This technology is based on the following psychological principle: teaching and learning which systematically involves students into the process of solving problems and problematic tasks built on the ground of the discipline content. This type of teaching and learning successfully combines regular students' independent research and their assimilation of the readymade knowledge from the teacher.

Problem-based teaching is also reflected in the structure and content of such electronic environment tools as "Lecture" and "Seminar". The problem-based lectures of the electronic course are focused on the independent work of students in the electronic environment. The peculiarity of the lecture material in the electronic course is that it is supported by control problem-based questions and discussions of the lecture material. The questions that are embedded into the structure of the electronic lecture and a test at the very end of the lecture enable using this tool most effectively.

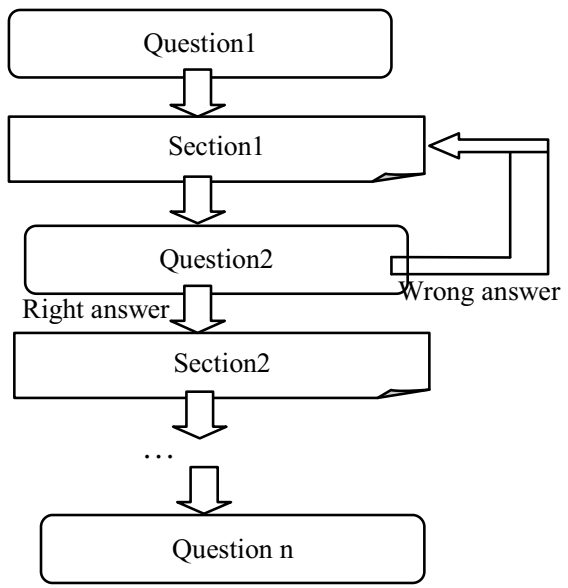

Fig. 1. The problem-based lecture structure.

Figure 1 demonstrates the structure of the problembased lecture where information sections (Section1, Section2, etc.) interchange with question sessions (Question1, Question2, etc.). The problem-based lecture starts with setting a problem - a question to activate the student's background knowledge on the topic of the lecture, the question is followed by a section of theoretical material, which allows the students to take the point of the problem presented in the question. Each information section is followed by another question, which allows the teacher to estimate how well the student has assimilated the material of the section. If the student submits the right answer, then he moves to the next information section. If the answer provided is wrong, the student has to study the material one more time and as many times as it is necessary for her/him to get the point. The determining feature of the problembased lecture is setting and solving simulated learning problems with various degree of students' participation in the process.

A problem-based seminar is an active teaching method which guarantees intensive engagement of all the students in the group as presenters. The presentations are further discussed with a question-and-answer session to follow. The aim of the problem-based seminar is to elicit as many points of view as possible and to develop the students' critical thinking skills.

In the "Seminar" tool each student is provided with an individual task and an opportunity to assess and comment on the works of other students on the basis of the assessment rubric presented by the teacher. At the end of the seminar work the student answers the questions from his opponents, agrees or disagrees with the assessment provided giving his own reasons. Such work implies high level of participation from each student. To organize and manage the "Seminar" functions and students' work in it the teacher provides a well-defined task and detailed assessment rubric. The teacher is to follow the students in the seminar work to see if everyone is engaged or any help is required and moderate the work process, provide feedback by means of other electronic tools. The problem-based seminar can maintain a perfect opinion-exchange activity and a collective search of various ways of solving the problems in individual tasks.

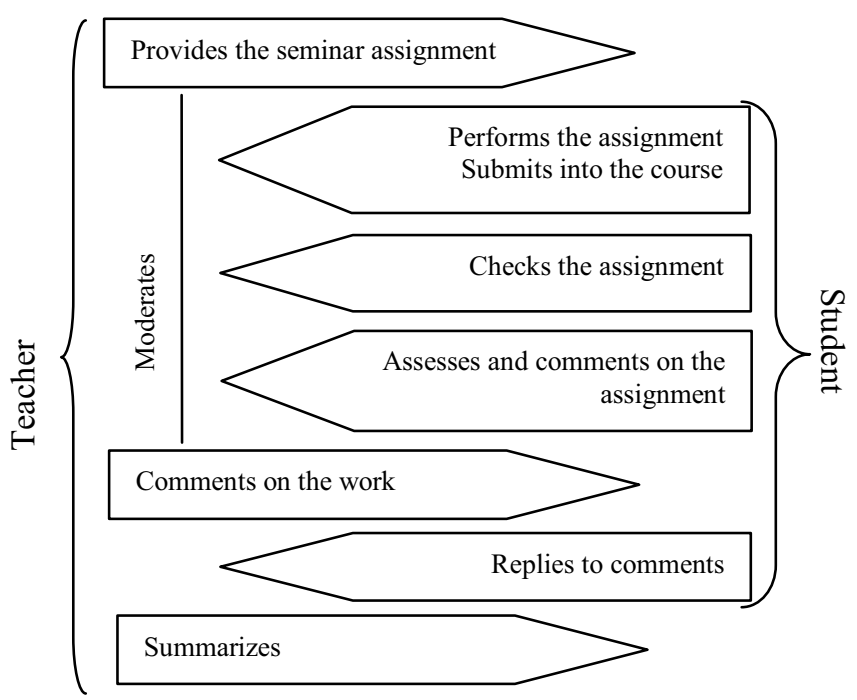

Fig. 2. The structure of the electronic problem-based seminar

Figure 2 illustrates the structure of the problem-based seminar in the electronic course. The teacher's 
performance and the students' activities are indicated on the left and the right respectively. The teacher sets the individual assignments and provides a detailed instruction on what the students have to do. They do their tasks and submit them for further assessment by other assigned students. Each student has to analyse and assess at least one work of a group-mate. They try to find the possible errors and assess the work according to the assessment rubric provided in the task. Their assessment is to be commented on and the good arguments should be provided to prove the mark. The teacher observes the entire process and interrupts or comments if any challenges appear. After all the tasks have been assessed and commented on, the students reconsider their own individual assignments to agree or disagree with the assessment and defend their point of view. Finally, the teacher draws the conclusion and clarifies what went well and how the errors can be corrected. The teacher also gives the final mark. So the problem-based seminar engages all the students of the group.

One more method of active teaching used in the electronic course is a group tutorial which is organized as a "Forum". All the participants of the forum can asks questions and partake in the discussion. The teacher suggests the topic for discussion and directs the process by asking questions to encourage the discussion and assists in finding the right answer. The group tutorial appears especially effective on the completion of studying the discipline (module) of the fundamental character, such as "Mathematical Modeling" [8].

One of the most important aims of the teacher is to instruct students how to avoid plagiarism. To solve the problem of such copying from other students, learners are assigned individual tasks as homework [9]. To differentiate the background training of students, some learners may be given more complicated assignments with various ways of solution.

The teaching and learning process with problembased tasks in the classroom is often supported by the materials of the electronic course. It is especially significant at the initial stage, when the students' digital literacy skills are not developed enough and their learning should be carefully supervised by the teacher. Classroom work is also supplemented by the following active methods of teaching:

- demonstrating the process of solving a problem of mathematical modeling by the teacher or by one of the students, possibly, in the form of a mini-lecture;

- studying a fragment of the teaching material by a student followed by a demonstration and further discussion of the material;

- arranging a team or individual competition to achieve a better combination of various parameters in developing software: the speed of development, quantity of errors, code efficiency and resource saving;

- conducting the game "Find the error". The rules of the game are the following: one of the participants makes a deliberate mistake in the mathematical model or the program code / clean code. Other participants try to find the error. The speed of solving the problem is assessed. The team, or individual, who finds the error faster, is announced the winner [10].
A greater accent is made on the visibility of the material and feasibility of the blended course tasks. The material is supported by short videos in the electronic environment. Basic tasks are further developed into creative searching and tasks for critical thinking development. This approach enables increasing the efficiency of the material assimilation and promotes shaping the competencies of solving tasks independently.

Material design and development, i.e. recording videos, uploading the materials into the electronic environment, etc., is definitely time and effort consuming, but it is well compensated during the teaching and learning process in terms of managing the classroom and online studies.

\section{Conclusion}

The use of electronic environment in delivering a blended course in English for international students has a number of advantages in terms of organization of classroom and independent work. Students get an opportunity to study authentic materials, adopted by the teacher, consolidate the knowledge received through a set of specifically developed exercises. These exercises are focused on shaping skills of autonomous work to solve the tasks by creative and searching methods. The developed video lessons enable personification of the process of teaching and learning and enhancing efficiency of the course.

\section{Acknowledgment}

The programme was realized and subsided within the framework of the Programme for enhancing Tomsk Polytechnic University's competitiveness. The results presented herein were obtained with the assistance of the Russian Foundation.

\section{References}

1. O.N. Oleynikova, Bulletin of MSRU. Series Pedagogics, 4 (2014)

2. P. Chubik, Strategic Programme of National Research Tomsk Polytechnic University Competitiveness Enhancement in the Group of Top Level World Research and Academic Institutions, (2013)

3. I.V. Slesarenko, L.A. Sivitskaya, Ye.N. Dudina, E.O.Frantcuzskaia, Professional Training of Students of a Technical University in a Foreign Language: Developing the Pedagogical and Language Skills of Teaching Staff, (2015)

4. S. Ryana, J. Kaufmanb, J. Greenhousec, R.Shed, J. Shie, Community College Journal of Research and Practice, 40, 4 (2016)

5. B.Rienties, L. Toetenel, Computers in Human Behavior, 60 (July 2016)

6. K Wilson, A. Narayan, An International Journal of Experimental Educational Psychology, 36, 2 (2016) 
7. A.D. Pravdina, Humanities Bulletin, 3, 29 (2015)

8. H. Stoeger, A. Ziegler, Metacognition and Learning 3, 3 (2008)

9. M. Misfeldt, U.T. Jankvist, M.S. Aguilar, Mathematics Education, 11, 2 (2016)

10. L.M. Almeida, L.A. Kato, Mathematics Education, 9, 1 (2014) 